\title{
Exosomal formulation of anthocyanidins against multiple cancer types
}

Radha Munagala $^{1,2}$, Farrukh Aqil ${ }^{1,2}$, Jeyaprakash Jeyabalan ${ }^{1}$, Ashish K. Agrawal ${ }^{1}$, Ashley M. Mudd ${ }^{3}$, Kyakulaga Al Hassan ${ }^{3}$, Inder P. Singh ${ }^{4}$, Manicka V. Vadhanam ${ }^{1}$ and Ramesh C. Gupta ${ }^{1,} 3^{*}$

${ }^{1}$ James Graham Brown Cancer Center, ${ }^{2}$ Department of Medicine, ${ }^{3}$ Department of Pharmacology and Toxicology, University of Louisville, Louisville, KY 40202, ${ }^{4}$ National Institute of Pharmaceutical Education and Research, S.A.S Nagar, India.

Key words: Milk exosomes, Anthocyanidins, Drug delivery, Anti-cancer, Antiinflammatory

${ }^{*}$ Corresponding author:

Ramesh C. Gupta, Delia Baxter II, Room 304E, University of Louisville, 580 S. Preston Street, Louisville, KY 40202. Email: rcgupta@louisville.edu; Tel: 502-852-3682; Fax: 502-852-3842. 


\section{Abstract}

Over the last two decades, berries and berry bioactives particularly anthocyanins and their aglycones anthocyanidins (Anthos) have demonstrated excellent anti-oxidant, antiproliferative, apoptotic and anti-inflammatory properties. However, their physicochemical and pharmacokinetic limitations such as low solubility, low permeability, and poor oral bioavailability are considered as unfavorable properties for development as drugs. Therefore there is a need to develop systems for efficient systemic delivery and robust bioavailability. To overcome this barrier, in this study we prepared nano-formulation of bilberry-derived Anthos using exosomes harvested from raw bovine milk. Exosomal formulation of Anthos enhanced antiproliferative and antiinflammatory effects compared with the free Anthos against various cancer cells in vitro. Our data also showed significantly enhanced therapeutic response of exosomal-Anthos formulation compared with the free Anthos against lung cancer tumor xenograft in nude mice. The Anthos showed no signs of gross or systemic toxicity in wild-type mice. Thus, exosomes provide an effective alternative for oral delivery of Anthos that is efficacious, cost-effective, and safe, and this regimen can be developed as a non-toxic, widely applicable therapeutic agent. 


\section{Introduction}

Many plant bioactives suffer from notoriously poor bioavailability and instability [1-4] and therefore have failed to shine their full potential despite high doses. Several strategies have been investigated in order to achieve clinical efficacy of drugs with poor bioavailability and stability. Lately, new concepts from the field of nanotechnology have been utilized to overcome the challenge of poor absorption especially for oral delivery and enhancing the outcome of chemopreventives which is often referred to as 'nanochemoprevention' [5,6]. Nano-formulations of agents such as curcumin [7,8], EGCG $[9,10]$ and resveratrol $[11,12]$ has been explored as polymeric micelles, liposome/phospholipid, nano-/micro-emulsions, nanogels, solid lipid nanoparticles, polymer conjugates, etc. Although, some successful liposomal formulations of drugs. [e.g., doxorubicin (DoxilR)] have made to clinic, others have suffered from limitations of reproducibly and/or toxicity [13]. Unmodified liposomes are unstable in vivo with short blood circulation time, and lack of target selectivity [14]. Other limitations of liposomal system include opsonization, change of pharmacokinetics in multiple-dosing regimen, etc. [15]. Polymer-based delivery systems offer advantages of linking various ligands, but its cost-effective production is nowhere in the vicinity. Moreover, there are serious toxicity concerns with the long-term use of polymeric nanoparticles [16]. Exosomes as nano-carriers have the potential to overcome these limitations $[17,18]$. We have exploited exosomes from bovine milk as biological nanoparticles to delivery agents of both hydrophilic and hydrophobic nature [19]. Additionally, milk exosomes as drug delivery vehicle has positive attributes of being in abundance, cost-effective, scalable and biocompatible. 
Berries and berry bioactives, particularly the colored pigments, anthocyanins and their aglycones anthocyanidins (Anthos), are well known for their anti-oxidant, antiproliferative, apoptotic and anti-inflammatory properties [20-27]. Anthocyanins are pigments responsible for red and blue hues of many fruits (e.g., berries), vegetables (e.g., purple potatoes), flowers (hibiscus) and grains (purple rice). Blueberry, blackberry, bilberry, raspberry, strawberry are especially rich sources of dietary anthocyanins [28]. Over 600 structurally distinct anthocyanins have been identified in nature $[29,30]$. The diversity of anthocyanins comes from the number and the position of: (i) hydroxyl $(\mathrm{OH})$ and methoxyl $\left(\mathrm{OCH}_{3}\right)$ groups ii) type of sugars, and (iii) type of aliphatic or aromatic acids attached to the sugar. There are approximately 17 Anthos of which 6 occur widely, namely, cyanidin (Cy), delphinidin (Dp), petunidin (Pt), peonidin (Pe), pelargonidin $(\mathrm{Pg})$, and malvidin (Mv) [28].

Accumulating evidence from our laboratory [20-24] and other researchers [25-27] strongly indicate its preventive and therapeutic activity against various cancer types [31,32]. There have been few attempts towards translation of berry bioactives in clinical trials using berry powder [33-35]. However, the amount of berry powder that needs to be consumed daily for therapeutic response is not readily translatable/practical; in addition nearly $60 \%$ berry powder is composed of sugars, which further limit target patient population. Berry extracts [36] and anthocyanins on other hand address these concerns with some positive effects on pre-neoplastic lesions or cancers of the oral cavity, esophagus and colon, however, it still faces the challenge of poor oral bioavailability and stability [2,36-39]. 
Anthocyanins are highly water-soluble molecules. Glycosylation confers increased stability and water solubility to the anthocyanins, and acylation of the sugar residues further improves anthocyanin stability [30]. However, these attributes make anthocyanins poorly bioavailable with limited absorption by passive diffusion. The absorption of anthocyanins across the intestine wall requires either a specific active transport mechanism or needs to be hydrolyzed to their aglycones form by the action of specific enzymes such as $\beta$-glucosidase, $\beta$-glucuronidase, and $\alpha$-rhamnosidase by the gut intestinal microflora [40]. In contrast, aglycones lacking sugar moieties are relatively more hydrophobic in nature which facilitates their passively diffusion across the mucosal epithelium [41].However, at the same time they exhibit considerable chemical instability. Presence of conjugated Anthos (Cy and Pe monoglucuronides) in the plasma as glucuronides has been reported in dietary berry-treated animals, suggesting that anthocyanins may, in part, be hydrolyzed to Anthos [42,43]. Other flavonoids have also been indicated to undergo similar hydrolysis by intestinal $\beta$-glucosidases [44], resulting in the release of their aglycone form. These observations suggest the aglycons of anthocyanins might have a role in biological activity and contribute to protective effects rendered by berry intake.

Our earlier work comparing anti-proliferative effects with purified extracts at anthocyanin and Anthos levels revealed significantly greater activity of anthocyanidins over anthocyanins $[21,45]$. Data from Mukhtar and colleagues, and other laboratories have shown different pharmacological properties of anthocyanidins [46-48]. In addition, we discovered that a mixture of individual Anthos ( $\mathrm{Dp}, \mathrm{Cy}, \mathrm{Pe}, \mathrm{Pt}$ and $\mathrm{Mv}$ ) produced synergistic antiproliferative, anti-tumor and anti-inflammatory effects compared to the 
individual moieties [21]. We propose that nano-formulation of Anthos will not only increase its stability and bioavailability resulting in enhanced therapeutic effects but will also facilitate clinical translation by overcoming limitations associated with the use of whole berries, berry powder and berry extracts. In this study, we investigated if exosomal formulation of Anthos (ExoAnthos) will enhance therapeutic efficacy compared with the free Anthos against multiple cancer cell lines. Our data showed that exosomal formulation significantly enhanced therapeutic responses compared with the free Anthos both in vitro and in vivo.

\section{Materials and Methods}

\subsection{Isolation of exosomes}

Exosomes were isolated from pooled raw milk from dozens of mid-lactation, pastureraised Jersey cows, procured from a local dairy as described previously $[19,49]$. Briefly, exosomes were isolated by a sequential centrifugation process. Milk was first centrifuged at $13,000 \times \mathrm{g}$ for $30 \mathrm{~min}$ to remove fat and casein debris. Whey thus obtained was centrifuged at $100,000 \times \mathrm{g}$ for $60 \mathrm{~min}$ to remove larger microvesicles. Finally, the resulting supernatant was centrifuged at $135,000 \times \mathrm{g}$ for $90 \mathrm{~min}$ to obtain exosomal pellet and suspended in PBS. The protein concentration was determined using BCA kit (Thermo Scientific, Rockford, IL); exosome solutions were stored in aliquots of $\leq 6 \mathrm{mg}$ exosomal proteins $/ \mathrm{ml}$ at $-80^{\circ} \mathrm{C}$ until use. As indicated in our previous publication [19], exosomes isolated from several batches of milk isolated at different times resulted in similar yields and exosomal markers. 


\subsection{Isolation of berry Anthos}

Native mixture of Anthos was isolated from standardized anthocyanin-enriched extract of bilberry (Indena, S.A.S., Paris, France) by extraction of anthocyanins in $1 \% \mathrm{HCl}$, conversion of anthocyanins to Anthos in the presence of $3 \mathrm{~N} \mathrm{HCl}$ at $90{ }^{\circ} \mathrm{C}$ for $1 \mathrm{~h}$, followed by extraction in 1-pentanol and precipitation of the Anthos with petroleum ether [50]. The isolated Anthos were finally purified by C18 Sep-Pak column which provided over $94 \%$ purity as analyzed by UPLC. The relative percentages of the individual anthocyanidins, as determined by UPLC against reference compounds, in the isolated Anthos and the original bilberry extract were similar. The relative anthocyanidin mixture contains $\mathrm{Dp}, \mathrm{Cy}, \mathrm{Mv}, \mathrm{Pe}$ and $\mathrm{Pt}$ in the ratio of 33:28:16:16:7 respectively.

Stock solution of the Anthos was prepared based on average molecular weight of the individual anthocyanidins present in the bilberry extract used. The average molecular weight was calculated based on the molecular weight of individual anthocyanidins and their proportions present in the mixture. The profile of bilberry Anthos has been previously shown [21].

\subsection{Preparation of Anthos-loaded exosomes}

To prepare exosomal formulation of Anthos (ExoAnthos), first Anthos were dissolved in a mixture of acetonitrile: ethanol $(1: 1 \mathrm{v} / \mathrm{v})$. Anthos solution was then added to the exosomes suspended in PBS at $6 \mathrm{mg} / \mathrm{ml}$ protein concentration by simple mixing. The solvent concentration was maintained at $\leq 10 \%$ of the total reaction mixture.. The selection of the solvent volume was based on our previous observation in which this concentration did not significantly affect the quality attributes of the exosomes [19]. 
After mixing the Anthos solution with exosomes, the mixture was kept at room temperature for approximately $15 \mathrm{~min}$, followed by low-speed centrifugation at $10,000 \mathrm{x}$ $\mathrm{g}$ for $10 \mathrm{~min}$ to remove any unbound Anthos. Anthos-loaded exosomes were collected by centrifugation at $135,000 \times \mathrm{g}$ for $90 \mathrm{~min}$. The ExoAnthos pellet thus obtained was suspended in PBS, centrifuged (10,000 $\mathrm{g}$ for $10 \mathrm{~min})$ to remove any residual unbound agent and passed through $0.22 \mu \mathrm{m}$ syringe filter to remove any microbial contamination. The formulation was stored in aliquots at $-80^{\circ} \mathrm{C}$ until use.

\subsection{Formulation characterization}

\subsubsection{Particle size and poly dispersity index (PDI) analysis}

Exosome and ExoAnthos formulations were diluted $(1 \mathrm{mg} / \mathrm{ml})$ in PBS and analyzed for particle size and PDI using a Zetasizer (Malvern Instruments Ltd, Malvern, Worcestershire, UK).

\subsubsection{Drug loading analysis}

The practical load of Anthos in the ExoAnthos formulation was determined by measuring the protein and Anthos concentrations. Briefly, $50 \mu \mathrm{l}$ of the Anthos formulation was mixed with $0.95 \mathrm{ml}$ acetonitrile to extract the Anthos and precipitate exosomal proteins. The precipitated proteins were separated by centrifugation (10,000 $\mathrm{x}$ $g$ for $10 \mathrm{~min})$, and supernatant containing the Anthos was analyzed by Highperformance liquid chromatography (HPLC). The pellet was suspended in PBS and exosomal proteins were analyzed by BCA method.

\subsubsection{HPLC analysis}


Samples $(15 \mu \mathrm{l})$ containing Anthos were analyzed by HPLC using a Shimadzu Premier C18 reverse-phase column $(250 \times 4.6 \mathrm{~mm}$ i.d., $5 \mu \mathrm{m})$. Mobile phase A, water: formic acid : acetonitrile (87:10:3) and B, water : formic acid : acetonitrile 40:10:50 were used at a flow rate of $0.6 \mathrm{ml} / \mathrm{min}$. The gradient condition was $0-5 \mathrm{~min}, 5 \% \mathrm{~B} ; 5-15 \mathrm{~min}, 15 \%$ B; $15-20$ min, $25 \%$ B; $20-30$ min, 35\% B; $30-40$ min, 45\% B, 40-45 min, 100\% B, 45-50 min, $5 \%$ B. Anthos were detected at $520 \mathrm{~nm}$ by PDA-UV and total Anthos concentration was calculated against a standard curve. Reference anthocyanidins used were purchased from Chromadex (Irvine, CA $)$.

\subsubsection{Atomic Force Microscopy (AFM) for morphology analysis}

The morphology of the exosomes and ExoAnthos were determined by AFM. Exosomes and ExoAnthos were diluted to $10 \mu \mathrm{g} / \mathrm{ml}$ using deionized water and then $2 \mu \mathrm{l}$ of the respective samples was placed on a silica wafer and air dried for $30 \mathrm{~min}$. AFM (Asylum MF-3D, Oxford Instruments, Goleta, CA) images were captured in tapping mode using aluminum-coated silicon probes. Topographic height, amplitude and phase retraces were imaged with a fixed force $(<1 \mathrm{nN})$ at a scanning rate of $1 \mathrm{~Hz}$. The images were processed using IGOR software.

\subsection{Storage stability}

Stability of the exosomes and ExoAnthos stored at $-80{ }^{\circ} \mathrm{C}$ was examined. Exosomes twelve days after the storage, triplicate samples were thawed and the aliquots were divided in two parts: one part was used for particle size and PDI measurement after appropriate dilution as described in section 2.4 while the other part was analyzed for Anthos content by UPLC. 


\subsection{In vitro studies}

\subsubsection{Cell culture}

Human lung cancer (A549 and H1299), breast cancer (MDA-MB-231 and MCF7), pancreatic (PANC1 and Mia PaCa2), Prostate (PC3 and DU145), colon (HCT116) and ovarian (OVCA432) cell lines were obtained from American Type Cell Culture (ATCC, Manassas, VA) or provided by colleagues at the University of Louisville Health Sciences, Louisville, KY. All cancer cell lines were supplemented with $10 \%$ fetal bovine serum and $1 \%$ antibiotics (Penicillin/Streptomycin). The A549 and PC3 cells were grown in F-12K media. The MCF7, Panc1 and Mia PaCa2 received Dulbecco's Modified Eagle's Medium (DMEM). Media for MCF7 cells was also supplemented with 0.2 units/ml insulin. MDA-MB-231 cells were grown in L-15 media. The $\mathrm{H} 1299$ and OVCA432 received RPMI media, DU145 were maintained in Eagle's Minimum Essential Medium (EMEM) and HCT116 received McCoy's Medium. All cell lines were maintained at $37^{\circ} \mathrm{C}$ in a humidified chamber at $5 \% \mathrm{CO}_{2}$ except MDA-MB-231 which were grown in absence of $\mathrm{CO}_{2}$.

\subsubsection{Antiproliferative activity}

The antiproliferative activity of the Anthos, ExoAnthos and exosomes alone against various cancer cells was assessed by MTT assay, as described elsewhere [51]. Briefly, cells were seeded in a 96-well plate and treated with either Anthos, ExoAnthos or exosomes alone at various concentrations for $72 \mathrm{~h}$. At the end of treatment period the medium was replaced with media containing MTT $(0.5 \mathrm{mg} / \mathrm{ml})$ and incubated for $2 \mathrm{~h}$, followed by solubilization of formazan crystals with DMSO and spectrophotometric 
measurement at $570 \mathrm{~nm} . \quad I_{50}$ values were calculated using CalcuSyn software Version 2.0 .

\subsubsection{Electrophoretic Mobility Shift Assay (EMSA)}

DNA binding of NF-KB was measured by EMSA as described [52]. Briefly, the H1299 and MCF7 cells pretreated with the Anthos or ExoAnthos at various concentrations (25 $200 \mu \mathrm{M})$ at $37^{\circ} \mathrm{C}$ for $24 \mathrm{~h}$ and then challenged with tumor necrosis factor- $\alpha$ (TNF- $\left.\alpha\right)(1$ $\mathrm{ng} / \mathrm{ml}$ ) [19]. Nuclear extracts were prepared and $20 \mu \mathrm{g}$ protein was incubated at room

temperature for $45 \mathrm{~min}$ with $0.2 \mu \mathrm{g}$ of ${ }^{32} \mathrm{P}$-end-labeled double-stranded oligonucleotide (5'-AGT TGA GGG GAC TTT CCC AGG C-3') containing the NF-KB binding motif (Promega, Madison, WI, USA) and $1 \mu \mathrm{g}$ of poly (dl-dC) as an inhibitor of nonspecific binding, in binding buffer (20 mM N-2-hydroxyethylpiperazine-N'-2 ethanesulfonic acid (HEPES; pH 7.4), $60 \mathrm{mM} \mathrm{KCl,} 5 \mathrm{mM} \mathrm{MgCl}$, $0.2 \mathrm{mM}$ EDTA, $0.5 \mathrm{mM}$ dithiothreitol, 0.5 $\mathrm{mM}$ phenylmehylsulfonyl fluoride, $1 \%$ Nonidet P-40 and $8 \%$ glycerol). In a coldcompetition experiment, unlabeled oligonucleotide was incubated with extracts for 30 min at room temperature prior to the addition of the radiolabeled probe. The reaction mixtures were electrophoresed through $7.5 \%$ native polyacrylamide gels and DNAprotein complexes were quantified by Packard Instantlmager (Downers Grove, IL).

\subsection{In vivo studies}

\subsubsection{Antitumor efficacy}

Female athymic nude (nu/nu) mice (5-6-week old) were procured from Harlan laboratories (Indianapolis, IN), maintained according to the Institutional Animal Care and Use Committee guidelines. Lung tumor xenografts were produced by subcutaneously 
injecting human lung A549 cells $\left(2.5 \times 10^{6}\right)$, in the left flank of the mice. Cells were suspended in serum-free media mixed with Matrigel matrix (Becton Dickinson, Bedford, MA) at 1:1 ratio. Animals were provided purified AIN93M diet and water ad libitum. Once the tumor volume reached about $80 \mathrm{~mm}^{3}$, animals were randomized into three groups: vehicle (PBS), Anthos (10 mg/kg b. wt.) and ExoAnthos (5 mg Anthos and 50 $\mathrm{mg}$ Exo protein $/ \mathrm{kg}$ b.wt.). The agents were administered three times a week (Mondays, Wednesdays and Fridays) by oral gavage. Diet consumption, body weight and tumor volume were measured weekly until termination of the study. The animals were euthanized by $\mathrm{CO}_{2}$ asphyxiation.

\subsubsection{Toxicity studies}

Wild-type female C57BL/6 mice (5-6 week old) were procured from Harlan laboratories and were randomized into two groups and treated daily with the vehicle (PBS) ( $n=4)$ or Anthos ( $8 \mathrm{mg} / \mathrm{kg} \mathrm{b}$. wt.) ( $\mathrm{n}=7$ ) by oral gavage daily, 5 times (Monday through Friday) a week. After three weeks, animals were euthanized by $\mathrm{CO}_{2}$ asphyxiation and blood was collected. Blood was analyzed for hematological parameters by using Cell Dyn 3500 hematology analyzer (Abbott laboratories, Santa Clara, CA) and liver and kidney function enzymes. Electrolyte analysis was done by using ion-selective electrode while

other biochemical parameters were analyzed spectrophotometrically by using AU640 Chemistry Immuno Analyzer (Beckman Coulter, Inc., Brea, CA).

\subsection{Statistical analysis}

Statistical analysis was performed with Graph Pad Prism statistical software (version 4.03; La Jolla, CA). Two-way ANOVA followed by Bonferroni post-test was used for 
xenograft study. Data in the xenograft studies is expressed as mean \pm standard error of mean (SEM) $(\mathrm{n}=8-10)$.

\section{Results}

\subsection{Characteristics of Anthos-loaded exosomes}

Exosomes isolated from bovine milk had average size of $79 \pm 5.2$. Exosomes loaded with Anthos exhibited insignificant increase with particle size of $83 \pm 1.7 \mathrm{~nm}$ as measured by zetasizer; the PDI of Exo and ExoAnthos was found to be 0.39 and 0.23 , respectively (Fig.1A). The practical drug loading was found to be $\sim 20 \%$ in ExoAnthos formulation. Surface morphology determination by AFM (Fig.1B) revealed that the spherical shape of exosome particles remained unaltered after Anthos loading in ExoAnthos formulations. The size of the exosomes and ExoAnthos determined by AFM analysis was, in fact, somewhat smaller (50-60 nm and 80-90 nm, respectively) compared with the size measured with zetasizer. Analysis of exosomes stored as frozen aliquots at $-80^{\circ} \mathrm{C}$ were found to essentially retain the Anthos stability as evident by the unaltered HLPC profiles (Fig. 2). There was no effect of storage on particle size and PDI as well.

\subsection{Anti-proliferative effects of exosomes alone on cancer cells}

We first determined the anti-proliferative effects of milk exosomes per se (in the absence of any drug) on cancer cell lines of lung, prostate, colon, breast, pancreatic and ovarian by MTT assay. The treatment of these cell lines with $50 \mu \mathrm{g} / \mathrm{ml}$ exosomal proteins for $72 \mathrm{~h}$ resulted in $8-47 \%$ cell growth inhibition (Fig. 3). Survival of lung cancer cells A459 and $\mathrm{H} 1299$ was reduced to $66 \%$ and $76 \%$; breast cancer cells MCF7 
and MDA-MB-231 showed cell survival of $55 \%$ and $76 \%$, respectively; both pancreatic cancer cells Panc1 and Mia Paca2 showed nearly $65 \%$ cell survival; prostate cancer cell line DU145 was the most sensitive with 53\% and PC3 cell were least affected with 92\% survival; while survival of ovarian cancer cells OVCA432 and colon cancer cells HCT116 was reduced to nearly $68 \%$ in each case. These findings indicate intrinsic anticancer activity of milk exosomes, which might be of additional benefit when exosomes are employed as vehicles to deliver anti-cancer drugs. We earlier reported exosomes alone had no cytotoxic effects on normal bronchial epithelial cells at $50 \mu \mathrm{g} / \mathrm{ml}$ exosomal protein concentration [19]. These protective effects are presumably related to some endogenous factors, e,g., therapeutic activity of complex of human milk-derived $\alpha$ lactalbumin and oleic acid (HAMLET) [53] and bovine milk-derived a-lactalbumin and oleic acid (BAMLET) [53-55] trigger tumor cell death.

\subsection{Anti-proliferative effects of Anthos and ExoAnthos on cancer cells}

Next we assessed the anti-proliferative effects of Anthos alone and in exosomal formulation on various cancer cell lines. The findings indicate that irrespective of the cancer cell type ExoAnthos had significantly higher anti-proliferative effects ( 4-180 fold decrease in $\mathrm{IC}_{50}$ Values) compared with the free Anthos (Fig.4). ExoAnthos also exhibited better dose-dependent anti-proliferative effects than Anthos alone. The $\mathrm{IC}_{50}$ values of the Anthos and ExoAnthos are shown in Table I. The observed enhanced in vitro anti-proliferative effects could be attributed to increased stability of the Anthos in media when loaded on to exosomes and higher cell uptake; part of the antiproliferative effects presumably resulted from the intrinsic activity of exosomes. 


\subsection{Anti-inflammatory effects of Anthos and ExoAnthos}

The nuclear factor NF-kB is a classic pro-inflammatory signaling molecule, as it plays a key role in the expression of pro-inflammatory genes such as cytokines, chemokines, and adhesion molecules [56]. We have earlier reported anti-inflammatory activity of Anthos [21]. Here we evaluated the effect of Anthos alone and in exosomal formulation against TNFa-induced NF-KB activity in lung (H1299) and breast (MCF7) cancer cells. The TNFa treatment resulted in nearly 6 -fold increase in the levels of NF-kB. Although Anthos exhibited ability to inhibit TNFa-induced NF-kB activity this effect was markedly enhanced when Anthos were delivered in exosomal formulation (Fig. 5). In case of the H1299 cells although, Anthos alone at $200 \mu \mathrm{M}$ completely knocked out TNFa-induced NF-kB levels, lower doses of Anthos had no effect on cells. When H1266 cells were treated with ExoAnthos there was dose-dependent inhibition of NF-kB. On other hand, the MCF7 cells showed inhibition of NF-KB activity; however, this effect was not concentration-dependent. Overall, ExoAnthos exhibited greater dose-dependent inhibition of NF-KB activity compared to the free Anthos.

\subsection{In vivo antitumor efficacy of Anthos and ExoAnthos}

We determined the antitumor efficacy of Anthos and ExoAnthos using athymic nude mice bearing subcutaneous lung cancer A549 xenografts and compared with exosomes alone. We did not observe any gross toxicity due to Anthos or ExoAnthos, as no significant change was observed in the body weight, diet consumption and the animal movement compared with the vehicle treatment. We have earlier shown modest antitumor effects when animals were treated with exosomes alone in comparison with vehicle (PBS) treatment [19]. In the current study compared to treatment with vehicle 
(PBS), Anthos $(10 \mathrm{mg} / \mathrm{kg}$ ) showed a slight but insignificant inhibition of the tumor growth. However, ExoAnthos (5 mg/kg Anthos and $50 \mathrm{mg}$ exosomal proteins $/ \mathrm{kg}$ ) showed a significant growth inhibition (Fig. 6). Noteworthy is that the Anthos concentration in ExoAnthos formulation at one half of the free Anthos was effective, while the free Anthos was ineffective. The growth inhibition became obvious after four weeks of ExoAnthos treatment with significant higher $(p<0.01)$ inhibition in subsequent weeks.

\subsection{Toxicity study}

Systemic toxicity of Anthos was evaluated using wild-type mice which received the Anthos (oral gavage; $8 \mathrm{mg} / \mathrm{kg}$, 5 times a week or $40 \mathrm{mg} / \mathrm{kg}$ weekly dose). Here we purposely used higher dose in comparison with anti-tumor study (weekly dose of 30 $\mathrm{mg} / \mathrm{kg}$ as free Anthos or $15 \mathrm{mg} / \mathrm{kg}$ in exosomal formulation). We have recently demonstrated non-toxicity of milk exosomes [19] hence comparisons were made to vehicle (PBS) control group. No signs of gross toxicity due to the Anthos were observed, as there was no significant change in the body weight, diet consumption and the animal movement compared with the vehicle treatment (data not shown). The effect of the Anthos on the hematological and serum biochemical parameters of liver and kidney functions were examined after three weeks of the treatment. As shown in Supplementary Fig.1, no difference in leukocytes, erythrocyte counts as well as liver and kidney function enzymes was observed in Anthos-treated animals and their levels were well within the normal physiological range of age-matched control animals. 


\section{Discussion}

Accumulating evidence indicate therapeutic effects of phytochemicals especially for the colored pigments from berries that exist as glycoside of anthocyanidins. Several studies examined the in vitro and in vivo efficacy and posited various underlying molecular mechanisms for the health benefits $[28,38,41]$. However their physicochemical and pharmacokinetic limitations such as low solubility, low permeability, and poor oral bioavailability $[2,3,39,40]$ is widely accepted. There are mixed views in the literature on absorption and bioavailability of anthocyanins and Anthos. Glycosylation and acylation are considered the two structural features that dramatically affect anthocyanin absorption and influences bioavailability [30]. Some studies demonstrated that anthocyanins are mostly absorbed in their intact glycoside forms, while other studies indicated that they are first metabolized by the gut microflora, and held in their aglycone anthocyanidins forms [40,43]. A search for clinical trials conducted with anthocyanins/anthocyanidins at ClinicalTrials.gov show at least 72 completed and ongoing studies that have made attempts to understand the bioavailability, pharmacokinetics and health effects. These studies indicate a serious interest for clinical translation of anthocyanins as a viable therapeutic agent. However, their propensity to undergo extensive metabolism and instability are considered unfavorable properties that limit its suitability for development as potential drugs.

Despite well-accepted poor bioavailability of anthocyanins and Anthos, only limited attempts have been made to develop formulations to address this issue. Previously Stoner and Mallery groups developed freeze-dried black raspberry (FBR) aqueous gel for topical application on premalignant oral lesions. Although the treatment resulted in 
histopathologic regression of lesions, the chemopreventive benefit was not observed in all trial participants [36]. In another attempt, this group formulated millicylindrical injectable implants of FBR ethanol extract using poly(DL-lactic-co-glycolic acid) (PLGA) and poly(DL-lactic acid) (PLA) for sustained delivery of chemopreventive FBR anthocyanins [37,57]. Although implantable vehicles alleviate concerns with multiple dosing schedules associated with gel formulations, this is not patient friendly. Oral delivery of drug is the most patient friendly with highest compliance. Recently, alginatebased in situ gastroretentive gelling [58] and microencapsulation with maltodextrin, whey protein isolate and beet pectin [59-61] systems are explored to increase stability, modulate the release and increase the retention time of anthocyanins.

Based on our published [21,45] and unpublished findings indicating Anthos to have higher therapeutic effect both in vitro and in vivo compared to anthocyanins, we believe that Anthos may be the biologically-active moieties and a superior candidate to anthocyanins for drug development. Anthos have been investigated only in limited studies compared to anthocyanins due to unavailability of pure compounds in large quantities. We have developed simple solvent-solvent extraction-based methods for the isolation of pure Anthos from enriched berry extracts [50]. Our experimental evidence also demonstrate synergistic activity of the native mixture of the five Anthos in bilberry, namely, Dp, Cy, Pu, Pe, Mv compared to individual entities [21]. Anthos are considered to be much prone to avid chemical decomposition than the glycoside counterparts. Therefore, they make a suitable candidate for nano-encapsulation to improve treatment efficacy. This report examines the exosomal formulation for oral delivery of Anthos with improved stability and anti-cancer effects. 
Exosomes are biological nanoparticles that are drawing great attention as drug delivery vehicle due to their cell-based origins [62-65]. Attempts have been made in the recent past to isolate exosomes from both non-cancerous and cancer cells in culture and fruit juices for delivering the chemotherapeutic drugs, doxorubicin $[66,67]$, paclitaxel $[68,69]$ and natural agents such as curcumin [70], withaferin A [19] and celastrol [49]. Bulk isolation and safety concerns are the major limitations of such approaches. Our laboratory has recently shown that bovine milk-derived exosomes as a safe alternative source and demonstrated incorporation of both plant bioactives and chemotherapeutic drugs [19] for enhanced therapeutic activity, and improved oral bioavailability. In this report, we prepared Anthos-loaded exosomes. No significant change in physical attributes such as size and PDI was observed between Anthos-loaded and naked exosomes. We postulate that the lipid and protein nature might, in part, play a role in drug loading on exosome; however passive diffusion of the drug in to the lumen of the exosomes cannot be ruled out.

Several studies, including our own, have reported anti-cancer effects of Anthos both in vitro and in vivo. In agreement with earlier reports we demonstrated in vitro antiproliferative activity of the Anthos against six different cancer cell types. The observed anti-proliferative effect of the Anthos was further enhanced with exosomal formulation by a nearly $4-180$-fold reduction in the $\mathrm{IC}_{50}$ values. Naked exosomes also exhibited intrinsic mild to modest anti-proliferative effects in all cancer cell lines tested; these findings were in-line with our previous observations [19]. However exosomes alone were relatively safe with no cytotoxic effects observed against normal cells [19]. This 
difference in response to milk exosomes by cancer and normal cells may be due to differential uptake, retention and response to internal payload of exosomes.

The activation NF-KB signaling pathway by inflammatory mediators like interleukins and cytokines has been reported in many cancers [56]. Anti-inflammatory effects of Anthos have been documented earlier by us [21]. Similarly, treatment with Anthos and ExoAnthos caused inhibition the TNFa-induced activation of NF-KB cancer cells. ExoAnthos manifested significantly greater inhibition of NF-kB activation than the free Anthos. Oral delivery of ExoAnthos also resulted in enhanced anti-tumor activity against lung cancer in nude mice. In view of experimental evidence suggesting improved stability of Anthos in exosomal formulation we postulate that the enhanced anticancer effects of ExoAnthos is likely to due to higher stability, faster uptake and/or slow release of Anthos from the exosomes. In addition, other prinicples such as passive targeting by EPR effect could also contribute to explain these results. Nevertheless, in-depth analysis of stability and release kinetics under various physiological conditions need to be performed rigorously to confirm the above findings.

Information on the toxicity of the Anthos of wild-type mice with a weekly dose of 40 $\mathrm{mg} / \mathrm{kg}$ had no effect on the hematological and serum biochemical parameters of liver and kidney functions indicating that the Anthos were well tolerated. In addition we have established and reported safety of milk exosomes in our earlier studies [19]. Although oral exosomal formulation of Anthos needs to be examined for tolerance and toxicity under chronic conditions, in view of the safety profile of Anthos and exosomes alone in our prior studies there is little concern that ExoAnthos would raise undesired effects. 
In summary, our report demonstrates improved stability and anti-cancer effects of exosomal formulation of the Anthos against multiple cancer types. The greater efficacy exhibited by exosomal formulation of Anthos, in part, comes from the intrinsic activity of naked exosomes, which is a 'bonus' effect not common to traditional drug delivery vehicles. Encapsulation of Anthos onto milk exosomes can achieve higher drug efficacy with no toxic side effects. Thus, exosomes provide an effective alternative for oral delivery of Anthos that is efficacious, cost-effective and safe for the treatment of multiple cancers.

\section{Abbreviations}

miRNA: microRNA; MTT: 3-(4,5-dimethylthiazol-2-yl)-2,5-diphenyl tetrazolium bromide; AFM: atomic force microscopy; Anthos: anthocyanidins; ExoAnthos: Exosomal formulation of Anthos; Cy: cyaniding; Dp: delphinidin; Pt: petunidin; Pe: peonidin; Pg: pelargonidin; Mv: malvidin; EMSA: Electrophoretic Mobility Shift Assay (EMSA); HPLC:

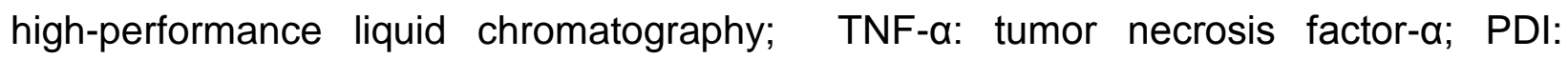
polydispersity index.

\section{Acknowledgements}

This work was supported by Department of Defense Breakthrough Award (W81XWH14-1-0269), Agnes Brown Duggan Endowment and Helmsley Trust Funds, awarded to R.C.G. Ms. Sarah Wilcher is thankfully acknowledged for oral gavage treatments during animal studies.

\section{References}


[1] Oliveira, H. et al. (2016). Bioavailability studies and anticancer properties of malvidin based anthocyanins, pyranoanthocyanins and non-oxonium derivatives. Food Funct 7, 2462-8.

[2] Lila, M.A., Burton-Freeman, B., Grace, M. and Kalt, W. (2016). Unraveling Anthocyanin Bioavailability for Human Health. Annu Rev Food Sci Technol 7, 375-93.

[3] McGhie, T.K. and Walton, M.C. (2007). The bioavailability and absorption of anthocyanins: towards a better understanding. Mol Nutr Food Res 51, 702-13.

[4] Oehlke, K., Adamiuk, M., Behsnilian, D., Graf, V., Mayer-Miebach, E., Walz, E. and Greiner, R. (2014). Potential bioavailability enhancement of bioactive compounds using food-grade engineered nanomaterials: a review of the existing evidence. Food \& Function 5, 1341-1359.

[5] Siddiqui, I.A. et al. (2009). Introducing nanochemoprevention as a novel approach for cancer control: proof of principle with green tea polyphenol epigallocatechin-3-gallate. Cancer Res 69, 1712-6.

[6] Siddiqui, I.A. and Sanna, V. (2016). Impact of nanotechnology on the delivery of natural products for cancer prevention and therapy. Mol Nutr Food Res 60, 133041.

[7] Yallapu, M.M., Jaggi, M. and Chauhan, S.C. (2012). Curcumin nanoformulations: a future nanomedicine for cancer. Drug Discov Today 17, 71-80.

[8] Ranjan, A.P., Mukerjee, A., Helson, L., Gupta, R. and Vishwanatha, J.K. (2013). Efficacy of liposomal curcumin in a human pancreatic tumor xenograft model: inhibition of tumor growth and angiogenesis. Anticancer Res 33, 3603-9. 
[9] Khan, N., Bharali, D.J., Adhami, V.M., Siddiqui, I.A., Cui, H., Shabana, S.M., Mousa, S.A. and Mukhtar, H. (2014). Oral administration of naturally occurring chitosan-based nanoformulated green tea polyphenol EGCG effectively inhibits prostate cancer cell growth in a xenograft model. Carcinogenesis 35, 415-23.

[10] Wang, D., Taylor, E.W., Wang, Y., Wan, X. and Zhang, J. (2012). Encapsulated nanoepigallocatechin-3-gallate and elemental selenium nanoparticles as paradigms for nanochemoprevention. Int J Nanomedicine 7, 1711-21.

[11] Shao, J., Li, X., Lu, X., Jiang, C., Hu, Y., Li, Q., You, Y. and Fu, Z. (2009). Enhanced growth inhibition effect of resveratrol incorporated into biodegradable nanoparticles against glioma cells is mediated by the induction of intracellular reactive oxygen species levels. Colloids Surf B Biointerfaces 72, 40-7.

[12] Caddeo, C., Teskac, K., Sinico, C. and Kristl, J. (2008). Effect of resveratrol incorporated in liposomes on proliferation and UV-B protection of cells. Int $\mathrm{J}$ Pharm 363, 183-91.

[13] Yang, F., Jin, C., Jiang, Y., Li, J., Di, Y., Ni, Q. and Fu, D. (2011). Liposome based delivery systems in pancreatic cancer treatment: from bench to bedside. Cancer Treat Rev 37, 633-42.

[14] Sadasivam, M., Avci, P., Gupta, G.K., Lakshmanan, S., Chandran, R., Huang, Y.Y., Kumar, R. and Hamblin, M.R. (2013). Self-assembled liposomal nanoparticles in photodynamic therapy. Eur J Nanomed 5, DOI: 10.1515/ejnm2013-0010. 
[15] Çağdaş, M., Sezer, A.D. and Bucak, S. (2014) Liposomes as Potential Drug Carrier Systems for Drug Delivery, Application of Nanotechnology in Drug Delivery, PhD. Ali Demir Sezer (Ed.), InTech, DOI: 10.5772/58459.

[16] Feng, L. and Mumper, R.J. (2013). A critical review of lipid-based nanoparticles for taxane delivery. Cancer Lett 334, 157-75.

[17] Kooijmans, S.A., Vader, P., van Dommelen, S.M., van Solinge, W.W. and Schiffelers, R.M. (2012). Exosome mimetics: a novel class of drug delivery systems. Int J Nanomedicine 7, 1525-41.

[18] Lakhal, S. and Wood, M.J. (2011). Exosome nanotechnology: an emerging paradigm shift in drug delivery: exploitation of exosome nanovesicles for systemic in vivo delivery of RNAi heralds new horizons for drug delivery across biological barriers. Bioessays 33, 737-41.

[19] Munagala, R., Aqil, F., Jeyabalan, J. and Gupta, R.C. (2016). Bovine milkderived exosomes for drug delivery. Cancer Lett 371, 48-61.

[20] Jeyabalan, J., Aqil, F., Munagala, R., Annamalai, L., Vadhanam, M.V. and Gupta, R.C. (2014). Chemopreventive and therapeutic activity of dietary blueberry against estrogen-mediated breast cancer. J Agric Food Chem 62, 3963-71.

[21] Kausar, H., Jeyabalan, J., Aqil, F., Chabba, D., Sidana, J., Singh, I.P. and Gupta, R.C. (2012). Berry anthocyanidins synergistically suppress growth and invasive potential of human non-small-cell lung cancer cells. Cancer Lett 325, 54-62.

[22] Ravoori, S., Vadhanam, M.V., Aqil, F. and Gupta, R.C. (2012). Inhibition of estrogen-mediated mammary tumorigenesis by blueberry and black raspberry. $\mathrm{J}$ Agric Food Chem 60, 5547-55. 
[23] Aiyer, H.S. and Gupta, R.C. (2010). Berries and ellagic acid prevent estrogeninduced mammary tumorigenesis by modulating enzymes of estrogen metabolism. Cancer Prev Res (Phila) 3, 727-37.

[24] Aiyer, H.S., Srinivasan, C. and Gupta, R.C. (2008). Dietary berries and ellagic acid diminish estrogen-mediated mammary tumorigenesis in $\mathrm{ACl}$ rats. Nutr Cancer 60, 227-34.

[25] Adams, L.S., Phung, S., Yee, N., Seeram, N.P., Li, L. and Chen, S. (2010). Blueberry phytochemicals inhibit growth and metastatic potential of MDA-MB-231 breast cancer cells through modulation of the phosphatidylinositol 3-kinase pathway. Cancer Res 70, 3594-605.

[26] Seeram, N.P., Adams, L.S., Zhang, Y., Lee, R., Sand, D., Scheuller, H.S. and Heber, D. (2006). Blackberry, black raspberry, blueberry, cranberry, red raspberry, and strawberry extracts inhibit growth and stimulate apoptosis of human cancer cells in vitro. J Agric Food Chem 54, 9329-39.

[27] Kanaya, N., Adams, L., Takasaki, A. and Chen, S. (2014). Whole blueberry powder inhibits metastasis of triple negative breast cancer in a xenograft mouse model through modulation of inflammatory cytokines. Nutr Cancer 66, 242-8.

[28] Skrovankova, S., Sumczynski, D., Mlcek, J., Jurikova, T. and Sochor, J. (2015). Bioactive Compounds and Antioxidant Activity in Different Types of Berries. Int $\mathrm{J}$ Mol Sci 16, 24673-706.

[29] Yousuf, B., Gul, K., Wani, A.A. and Singh, P. (2016). Health Benefits of Anthocyanins and Their Encapsulation for Potential Use in Food Systems: A Review. Critical Reviews in Food Science and Nutrition 56, 2223-2230. 
[30] Welch, C.R., Wu, Q. and Simon, J.E. (2008). Recent Advances in Anthocyanin Analysis and Characterization. Curr Anal Chem 4, 75-101.

[31] Kresty, L.A., Mallery, S.R. and Stoner, G.D. (2016). Black raspberries in cancer clinical trials: Past, present and future. J Berry Res 6, 251-261.

[32] Montrose, D.C. et al. (2011). Anti-inflammatory effects of freeze-dried black raspberry powder in ulcerative colitis. Carcinogenesis 32, 343-50.

[33] Stoner, G.D. et al. (2005). Pharmacokinetics of anthocyanins and ellagic acid in healthy volunteers fed freeze-dried black raspberries daily for 7 days. J Clin Pharmacol 45, 1153-64.

[34] Kresty, L.A., Frankel, W.L., Hammond, C.D., Baird, M.E., Mele, J.M., Stoner, G.D. and Fromkes, J.J. (2006). Transitioning from preclinical to clinical chemopreventive assessments of lyophilized black raspberries: interim results show berries modulate markers of oxidative stress in Barrett's esophagus patients. Nutr Cancer 54, 148-56.

[35] Kresty, L.A., Fromkes, J.J., Frankel, W.L., Hammond, C.D., Seeram, N.P., Baird, M. and Stoner, G.D. (2016). A phase I pilot study evaluating the beneficial effects of black raspberries in patients with Barrett's esophagus. Oncotarget DOI: 10.18632/oncotarget.10457

[36] Mallery, S.R. et al. (2014). Topical application of a mucoadhesive freeze-dried black raspberry gel induces clinical and histologic regression and reduces loss of heterozygosity events in premalignant oral intraepithelial lesions: results from a multicentered, placebo-controlled clinical trial. Clin Cancer Res 20, 1910-24. 
[37] Shumway, B.S. et al. (2008). Effects of a topically applied bioadhesive berry gel on loss of heterozygosity indices in premalignant oral lesions. Clin Cancer Res $14,2421-30$.

[38] Stoner, G.D. (2009). Foodstuffs for preventing cancer: the preclinical and clinical development of berries. Cancer Prev Res (Phila) 2, 187-94.

[39] Fang, J. (2014). Bioavailability of anthocyanins. Drug Metab Rev 46, 508-20.

[40] Kay, C.D. (2006). Aspects of anthocyanin absorption, metabolism and pharmacokinetics in humans. Nutr Res Rev 19, 137-46.

[41] Smeriglio, A., Barreca, D., Bellocco, E. and Trombetta, D. (2016). Chemistry, Pharmacology and Health Benefits of Anthocyanins. Phytother Res 30, 1265-86.

[42] Hassimotto, N.M., Genovese, M.I. and Lajolo, F.M. (2008). Absorption and metabolism of cyanidin-3-glucoside and cyanidin-3-rutinoside extracted from wild mulberry (Morus nigra L.) in rats. Nutr Res 28, 198-207.

[43] Talavera, S., Felgines, C., Texier, O., Besson, C., Gil-Izquierdo, A., Lamaison, J.L. and Remesy, C. (2005). Anthocyanin metabolism in rats and their distribution to digestive area, kidney, and brain. J Agric Food Chem 53, 3902-8.

[44] Day, A.J. et al. (2000). Dietary flavonoid and isoflavone glycosides are hydrolysed by the lactase site of lactase phlorizin hydrolase. FEBS Lett 468,166 70.

[45] Aqil, F., Gupta, A., Munagala, R., Jeyabalan, J., Kausar, H., Sharma, R.J., Singh, I.P. and Gupta, R.C. (2012). Antioxidant and antiproliferative activities of anthocyanin/ellagitannin-enriched extracts from Syzygium cumini L. (Jamun, the Indian Blackberry). Nutr Cancer 64, 428-38. 
[46] Afaq, F. et al. (2007). Delphinidin, an anthocyanidin in pigmented fruits and vegetables, protects human HaCaT keratinocytes and mouse skin against UVBmediated oxidative stress and apoptosis. J Invest Dermatol 127, 222-32.

[47] Hafeez, B.B. et al. (2008). A dietary anthocyanidin delphinidin induces apoptosis of human prostate cancer PC3 cells in vitro and in vivo: involvement of nuclear factor-kappaB signaling. Cancer Res 68, 8564-72.

[48] Seeram, N.P., Zhang, Y. and Nair, M.G. (2003). Inhibition of proliferation of human cancer cells and cyclooxygenase enzymes by anthocyanidins and catechins. Nutr Cancer 46, 101-6.

[49] Aqil, F., Kausar, H., Agrawal, A.K., Jeyabalan, J., Kyakulaga, A.-H., Munagala, R. and Gupta, R. (2016). Exosomal formulation enhances therapeutic response of celastrol against lung cancer. Experimental and molecular pathology 101, 1221.

[50] Gupta, R.C. (2015). Method for isolation of bulk anthocyanidins and other bioactives. Patent number - US8987481 B1

[51] Munagala, R., Kausar, H., Munjal, C. and Gupta, R.C. (2011). Withaferin A induces p53-dependent apoptosis by repression of HPV oncogenes and upregulation of tumor suppressor proteins in human cervical cancer cells. Carcinogenesis 32, 1697-705.

[52] Paul, P.K., Gupta, S.K., Bhatnagar, S., Panguluri, S.K., Darnay, B.G., Choi, Y. and Kumar, A. (2010). Targeted ablation of TRAF6 inhibits skeletal muscle wasting in mice. J Cell Biol 191, 1395-411. 
[53] Hoque, M., Dave, S., Gupta, P. and Saleemuddin, M. (2013). Oleic Acid May Be the Key Contributor in the BAMLET-Induced Erythrocyte Hemolysis and Tumoricidal Action. PLoS One 8, e68390.

[54] Liskova, K., Kelly, A.L., O'Brien, N. and Brodkorb, A. (2010). Effect of denaturation of alpha-lactalbumin on the formation of BAMLET (bovine alphalactalbumin made lethal to tumor cells). J Agric Food Chem 58, 4421-7.

[55] Rammer, P. et al. (2010). BAMLET activates a lysosomal cell death program in cancer cells. Molecular Cancer Therapeutics 9, 24-32.

[56] Lawrence, T. (2009). The nuclear factor NF-kappaB pathway in inflammation. Cold Spring Harb Perspect Biol 1, a001651.

[57] Desai, K.G., Olsen, K.F., Mallery, S.R., Stoner, G.D. and Schwendeman, S.P. (2010). Formulation and in vitro-in vivo evaluation of black raspberry extractloaded PLGA/PLA injectable millicylindrical implants for sustained delivery of chemopreventive anthocyanins. Pharm Res 27, 628-43.

[58] Celli, G.B., Brooks, M.S.L. and Ghanem, A. (2016). Development and evaluation of a novel alginate-based in situ gelling system to modulate the release of anthocyanins. Food Hydrocolloids 60, 500-508.

[59] Arroyo-Maya, I.J. and McClements, D.J. (2015). Biopolymer nanoparticles as potential delivery systems for anthocyanins: Fabrication and properties. Food Research International 69, 1-8.

[60] Idham, Z., Muhamad, I.I. and Sarmidi, M.R. (2012). Degradation Kinetics and Color Stability of Spray-Dried Encapsulated Anthocyanins from Hibiscus Sabdariffa L. Journal of Food Process Engineering 35, 522-542. 
[61] Berg, S., Bretz, M., Hubbermann, E.M. and Schwarz, K. (2012). Influence of different pectins on powder characteristics of microencapsulated anthocyanins and their impact on drug retention of shellac coated granulate. Journal of Food Engineering 108, 158-165.

[62] Batrakova, E.V. and Kim, M.S. (2015). Using exosomes, naturally-equipped nanocarriers, for drug delivery. J Control Release 219, 396-405.

[63] Ha, D., Yang, N. and Nadithe, V. (2016). Exosomes as therapeutic drug carriers and delivery vehicles across biological membranes: current perspectives and future challenges. Acta Pharm Sin B 6, 287-96.

[64] Johnsen, K.B., Gudbergsson, J.M., Skov, M.N., Pilgaard, L., Moos, T. and Duroux, M. (2014). A comprehensive overview of exosomes as drug delivery vehicles - endogenous nanocarriers for targeted cancer therapy. Biochim Biophys Acta 1846, 75-87.

[65] Ren, J., He, W., Zheng, L. and Duan, H. (2016). From structures to functions: insights into exosomes as promising drug delivery vehicles. Biomater Sci 4, 91021.

[66] Tian, Y., Li, S., Song, J., Ji, T., Zhu, M., Anderson, G.J., Wei, J. and Nie, G. (2014). A doxorubicin delivery platform using engineered natural membrane vesicle exosomes for targeted tumor therapy. Biomaterials 35, 2383-90.

[67] Jang, S.C. et al. (2013). Bioinspired exosome-mimetic nanovesicles for targeted delivery of chemotherapeutics to malignant tumors. ACS Nano 7, 7698-710.

[68] Kim, M.S. et al. (2016). Development of exosome-encapsulated paclitaxel to overcome MDR in cancer cells. Nanomedicine 12, 655-64. 
[69] Saari, H., Lazaro-lbanez, E., Viitala, T., Vuorimaa-Laukkanen, E., Siljander, P. and Yliperttula, M. (2015). Microvesicle- and exosome-mediated drug delivery enhances the cytotoxicity of Paclitaxel in autologous prostate cancer cells. $\mathrm{J}$ Control Release 220, 727-37.

[70] Sun, D. et al. (2010). A novel nanoparticle drug delivery system: the antiinflammatory activity of curcumin is enhanced when encapsulated in exosomes. Mol Ther 18, 1606-14. 


\section{Figure Legends}

Figure 1. Size and morphology of milk exosomes: Bovine milk-derived exosomes (Exo) and ExoAnthos formulation were analyzed for size by zetasizer (A). Diluted Exo and ExoAnthos suspensions were used for imaging by AFM. Topographic and amplitude images were captured concurrently with a fixed force $(<1 \mathrm{nN})$ with a scanning rate of $1 \mathrm{~Hz}(\mathrm{~B})$.

Figure 2. Stability of Anthos in ExoAnthos: HPLC profile of Anthos extracted from exosomal formulation at day 0 and 12 days. The relative ration of delphinidin (Dp), cyanidin (Cy), petunidin (Pt), peonidin (Pe) and malvidin (Mv) was 40.1: 25.4: 15.8: 5.4: 12.8 (anthocyanidins reference), 37.6: 25.4: 16.9: 6.2: 13.8 (formulation at day 0) and 37.5: 25.3: 17.1: 6.0: 14.0 (formulation at day 12).

Figure 3. Intrinsic activity of bovine milk-derived exosomes to inhibit growth of various human cancer cell types: Cancer cell lines of lung, breast, ovarian, colon, pancreas and prostate were treated with $50 \mu \mathrm{g} / \mathrm{ml}$ exosomal proteins for $72 \mathrm{~h}$ and effect on cell growth inhibition was assessed by MTT assay and compared with untreated cells. Statistical analysis was performed using Student t-test to compare exosomes alone with vehicle treatment. ${ }^{*} p \leq 0.05 ;{ }^{* *} p \leq 0.01$ and ${ }^{* * *} p \leq 0.001$.

Figure 4. Anti-proliferative activity of Anthos-loaded exosomes (ExoAnthos) against various cancer cell types: Cancer cell lines of lung, breast, ovarian, colon, pancreas and prostate were treated with various concentrations of bilberry-derived 
Anthos or ExoAnthos for $72 \mathrm{~h}$ and effect on cell growth inhibition was assessed by MTT assay.

Figure 5. Anti-inflammatory activity of Anthos-loaded exosomes (ExoAnthos) against cancer cells: Lung and breast cancer cells were with indicated concentrations of Anthos or ExoAnthos for $24 \mathrm{~h}$ and effect on NFKB activity was assessed by EMSA. Panels on the bottom represent quantification of the band and expressed as fold change. Statistical analysis was performed using Student t-test to compare TNF- $\alpha+$ Anthos and TNF- $\alpha+$ ExoAnthos vs TNF- $\alpha$ alone group. ${ }^{* *} p \leq 0.01$ and ${ }^{* * *} p \leq 0.001$.

Figure 6. Anti-tumor activity of Anthos-loaded exosomes (ExoAnthos) against lung tumors: Following inoculation with A549 cells, nude mice were treated oral gavage three times a week with Exo-Anthos (5 mg Anthos and $50 \mathrm{mg}$ Exo protein/ $\mathrm{kg}$ bw). Three other groups were treated i.p. with Exo alone $(50 \mathrm{mg} / \mathrm{kg})$ or anthos $(10$ $\mathrm{mg} / \mathrm{kg})$. Data represent average \pm SE of means $(n=7-8)$. Significance of ExoAnthos vs. Exo alone group is shown.

Supplementary Figure 1. Systemic toxicity of Anthos: Wild-type female C57BL/6 mice (5-6 week old) were randomized into two groups and treated daily with the vehicle (PBS) $(\mathrm{n}=4)$ or Anthos ( $8 \mathrm{mg} / \mathrm{kg}$ b. wt.) $(\mathrm{n}=7)$ by oral gavage daily, 5 times a week for 5 weeks. Blood was analyzed for hematological parameters $(A)$ and biochemical parameters (B). Data represent average \pm SE of means. Statistical analysis performed 
using Student t-test revealed insignificant difference between Anthos- vs vehicle-treated mice. 
Figure 1

A

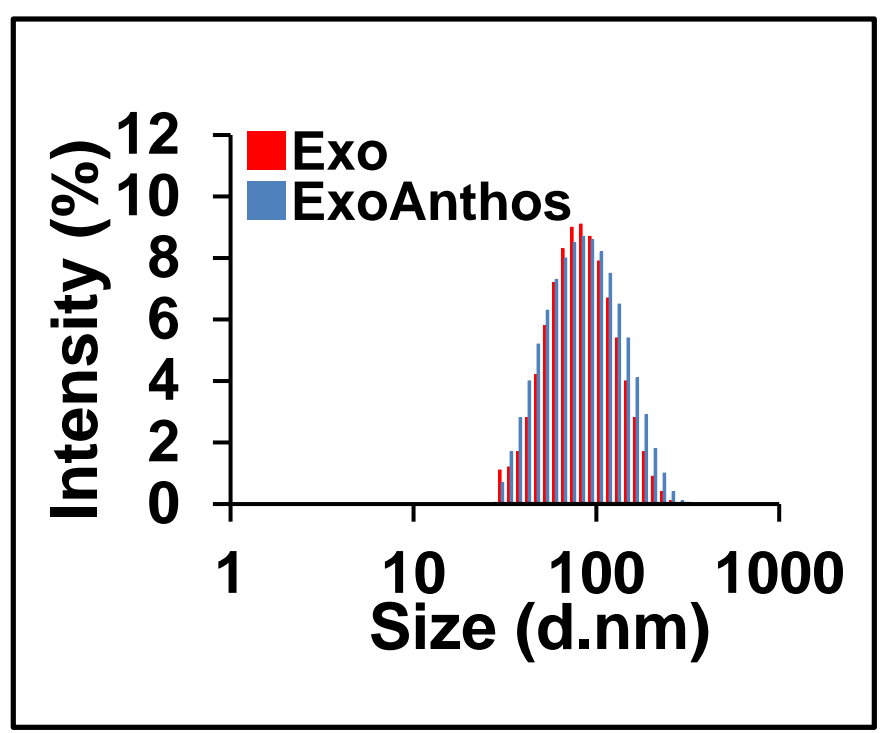

B

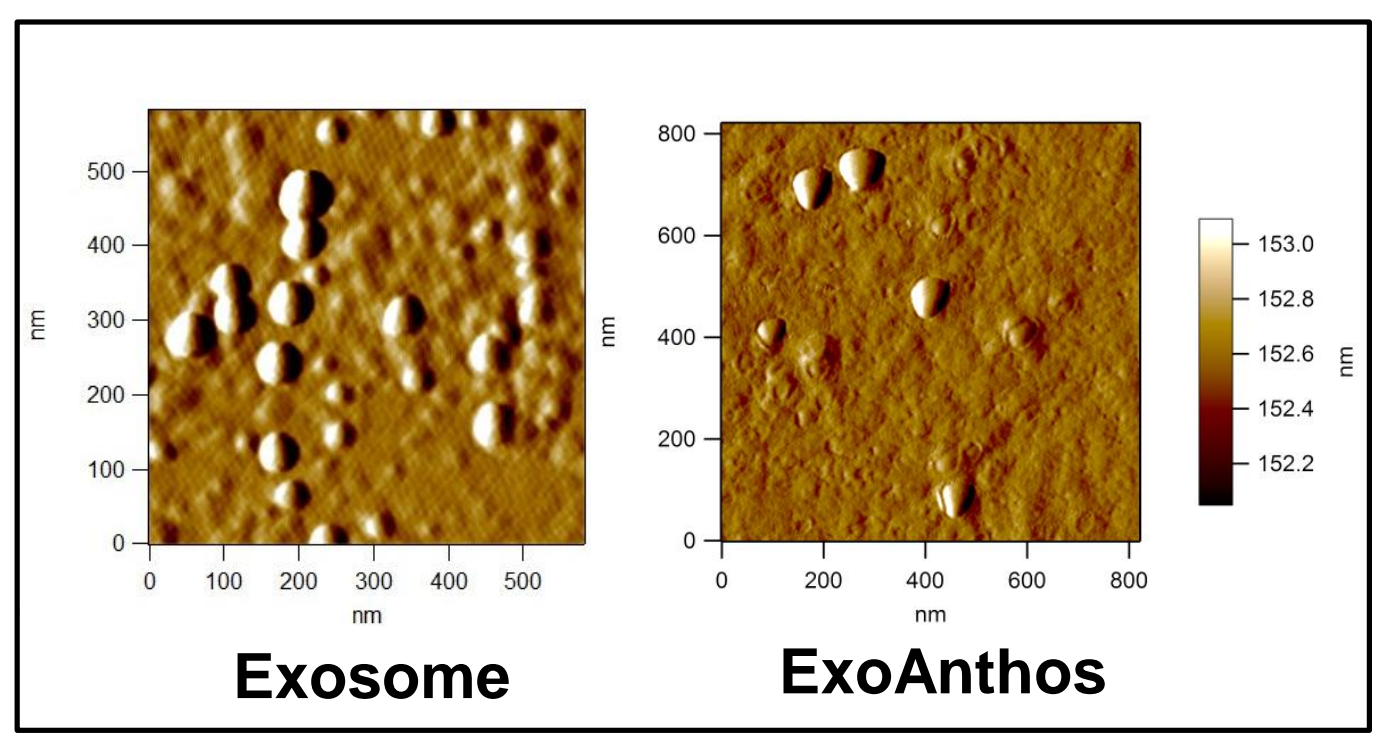


Figure 2

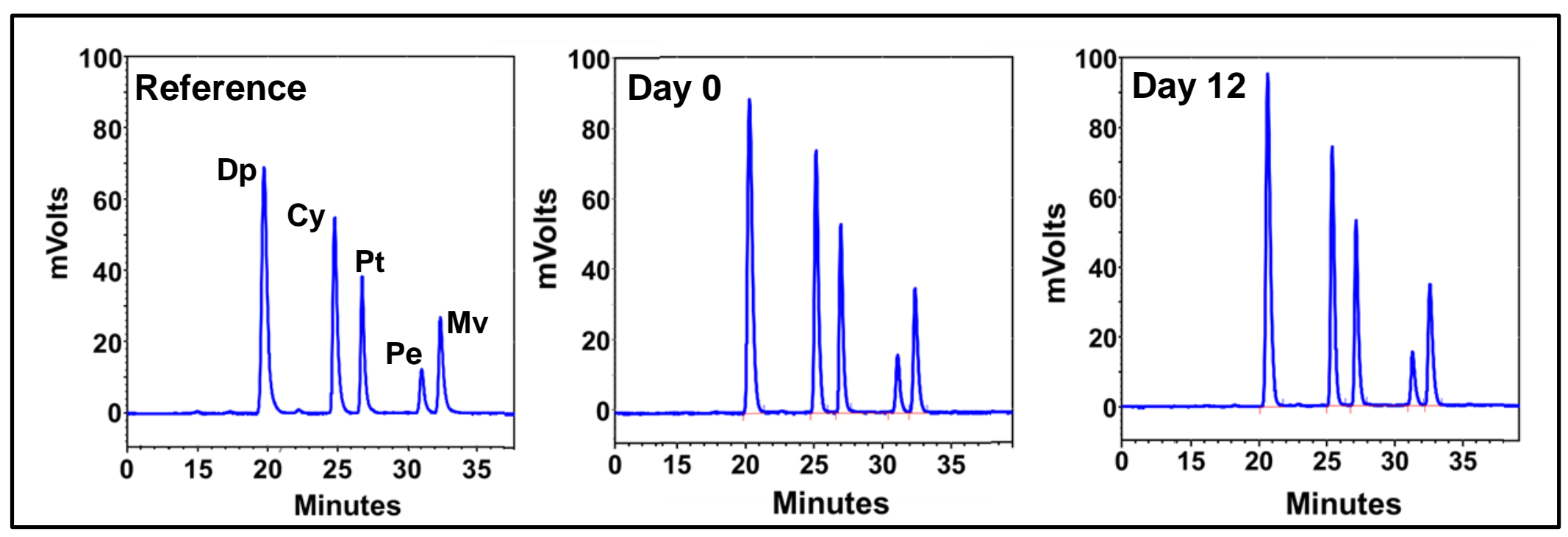


Figure 3

\section{$\$$ Vehicle $\square$ Exosome}
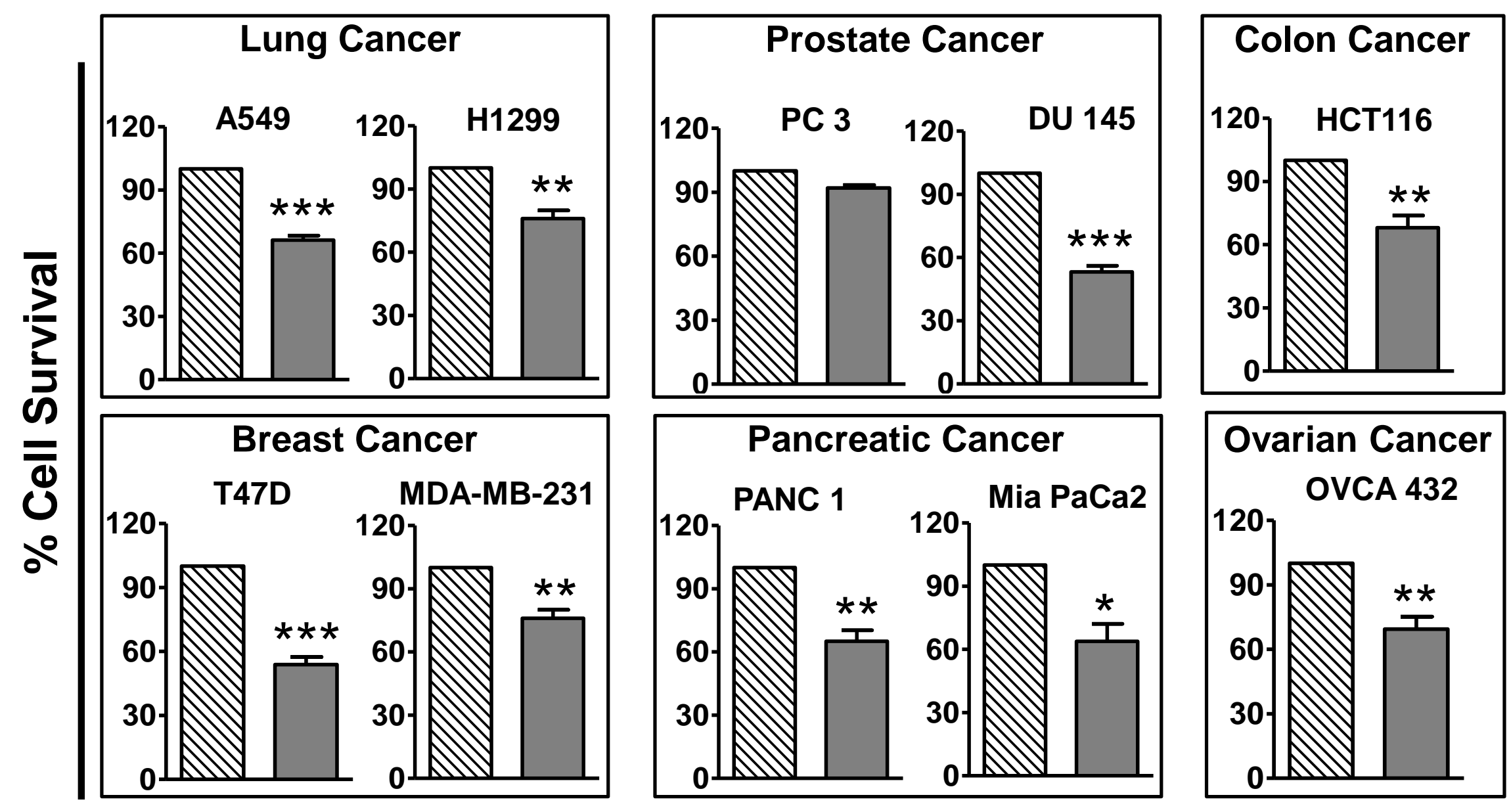
Figure 4

\section{$\rightarrow$ Anthos - -ExoAnthos}
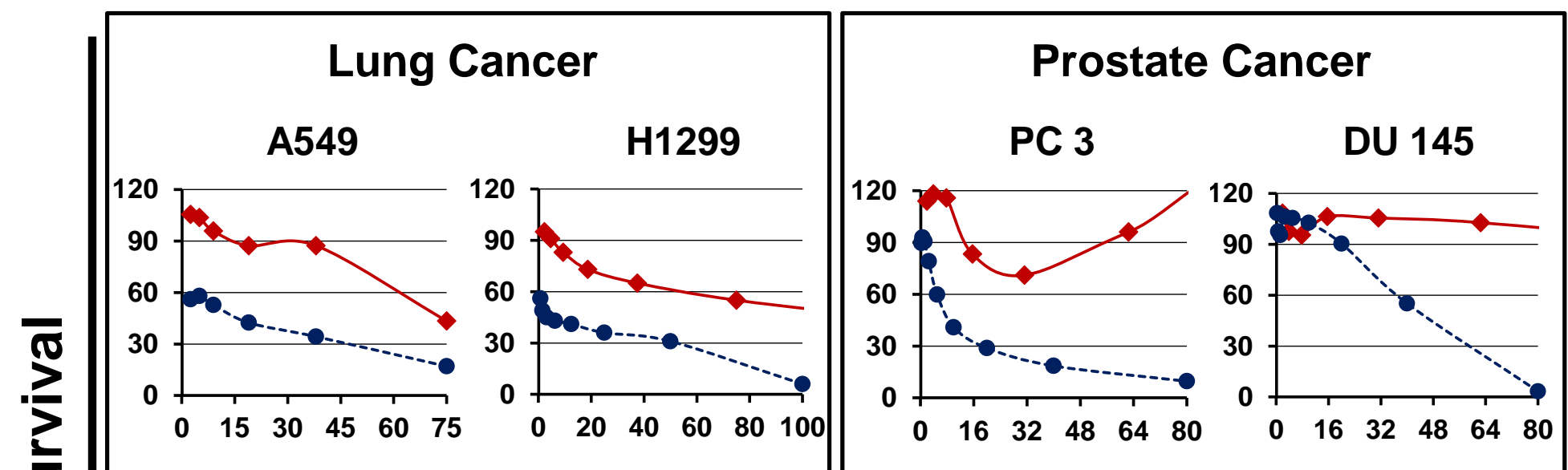

\section{Colon Cancer}
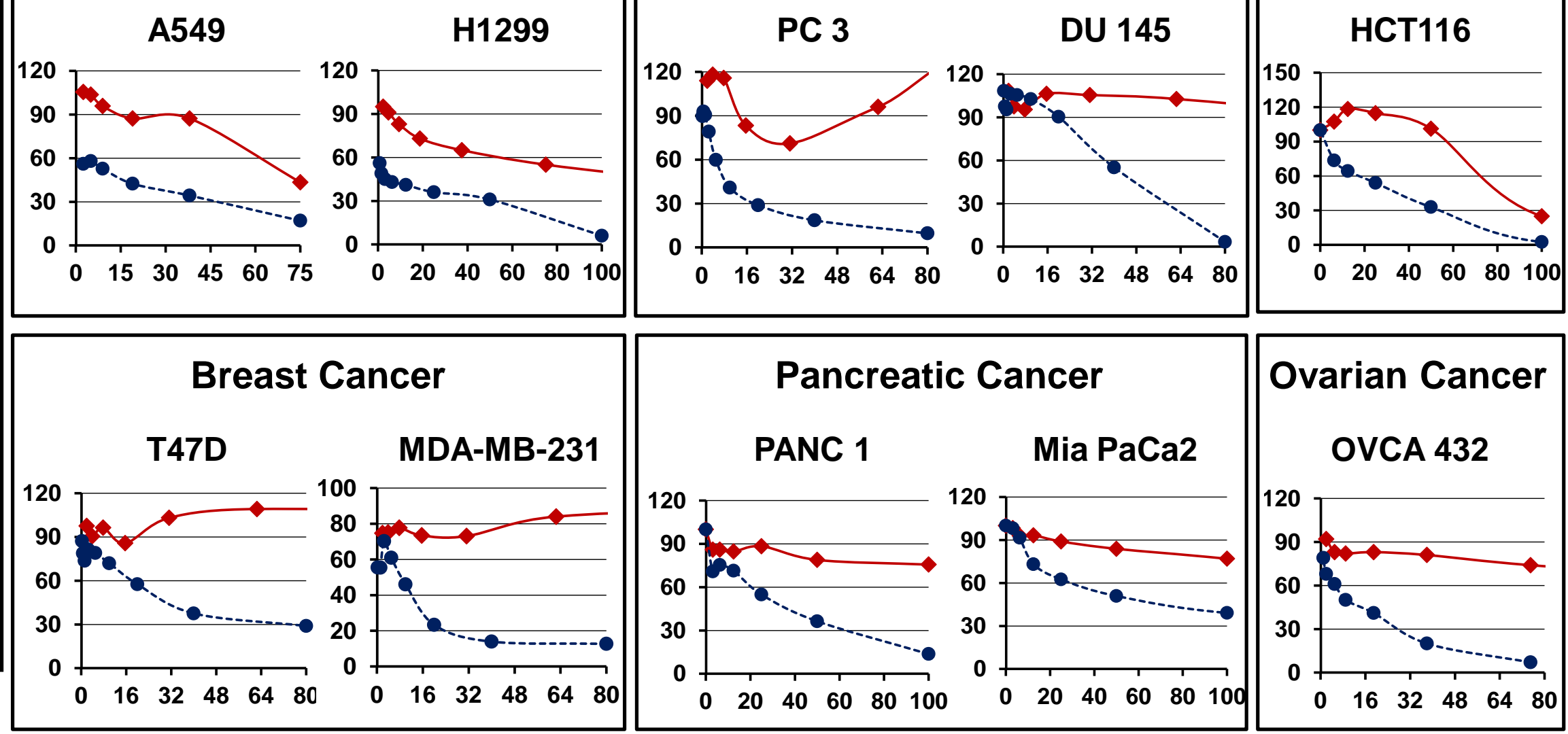

Ovarian Cancer

OVCA 432

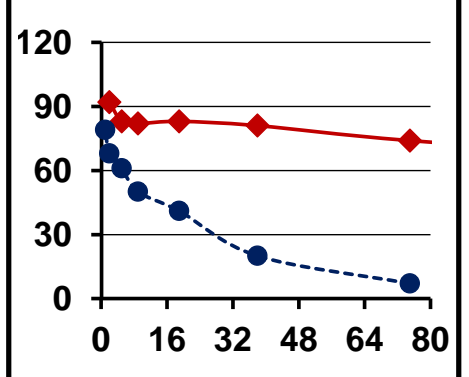

\section{Anthos $(\mu \mathrm{M})$}


Figure 5

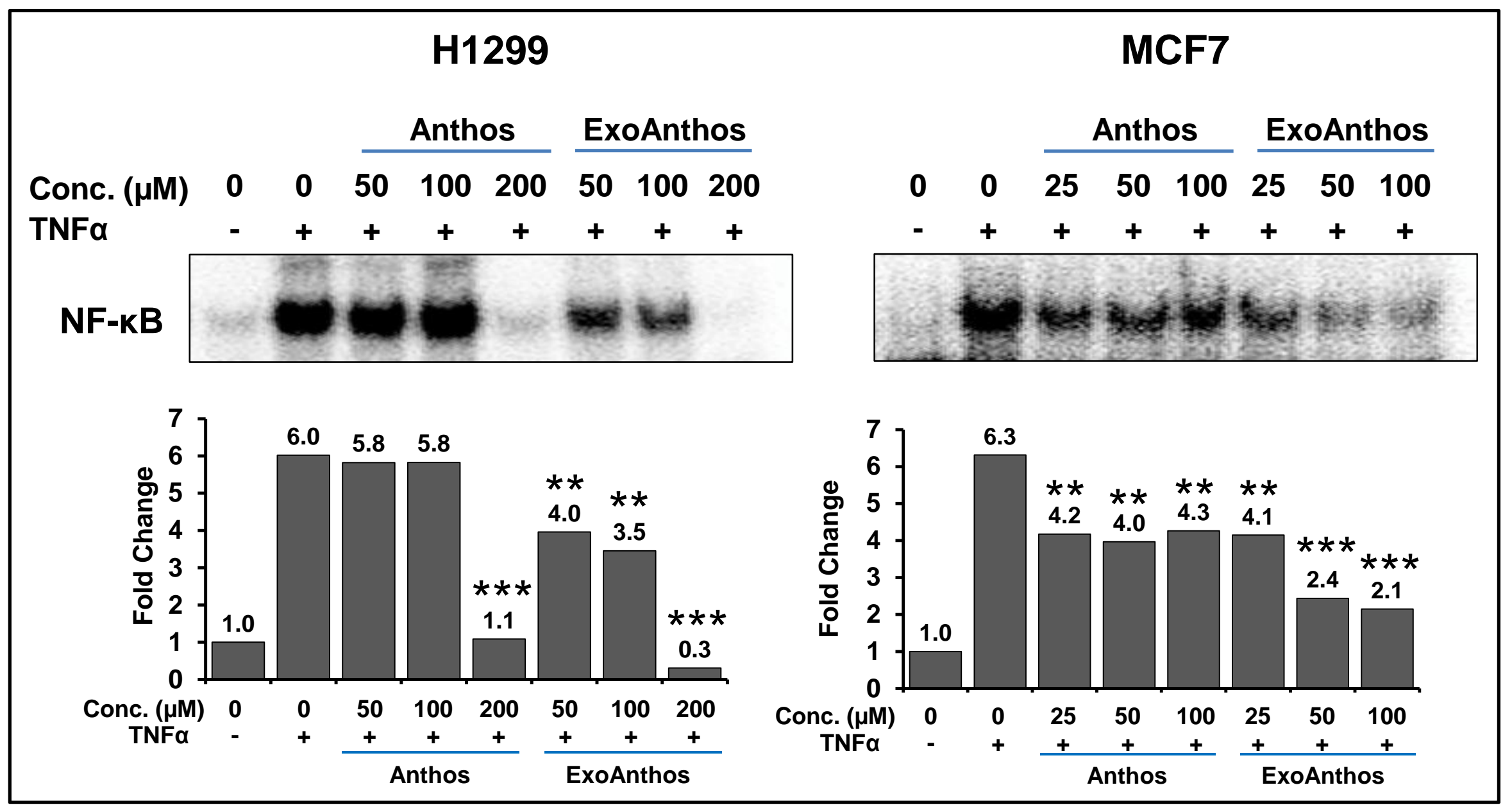


Figure 6

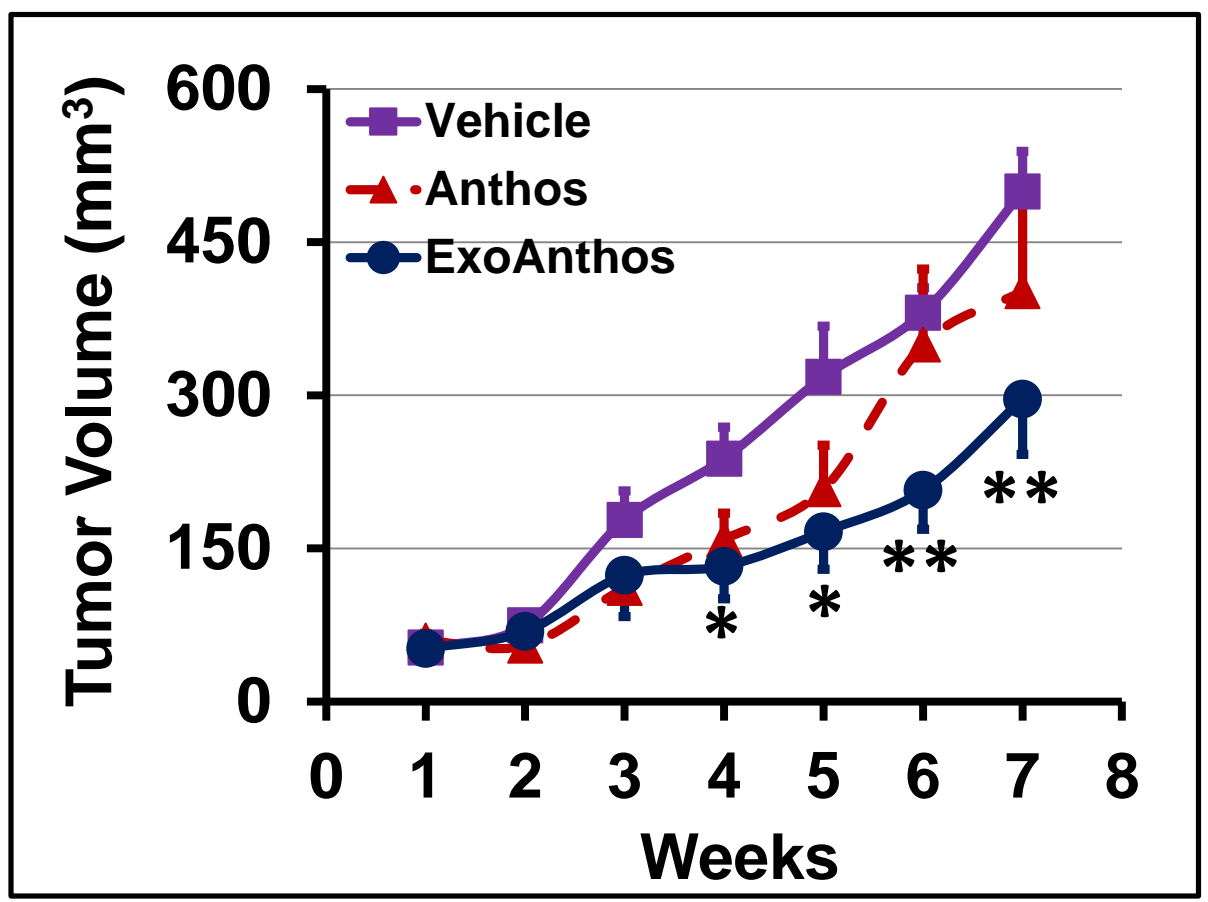




\section{Supplementary Figure 1}
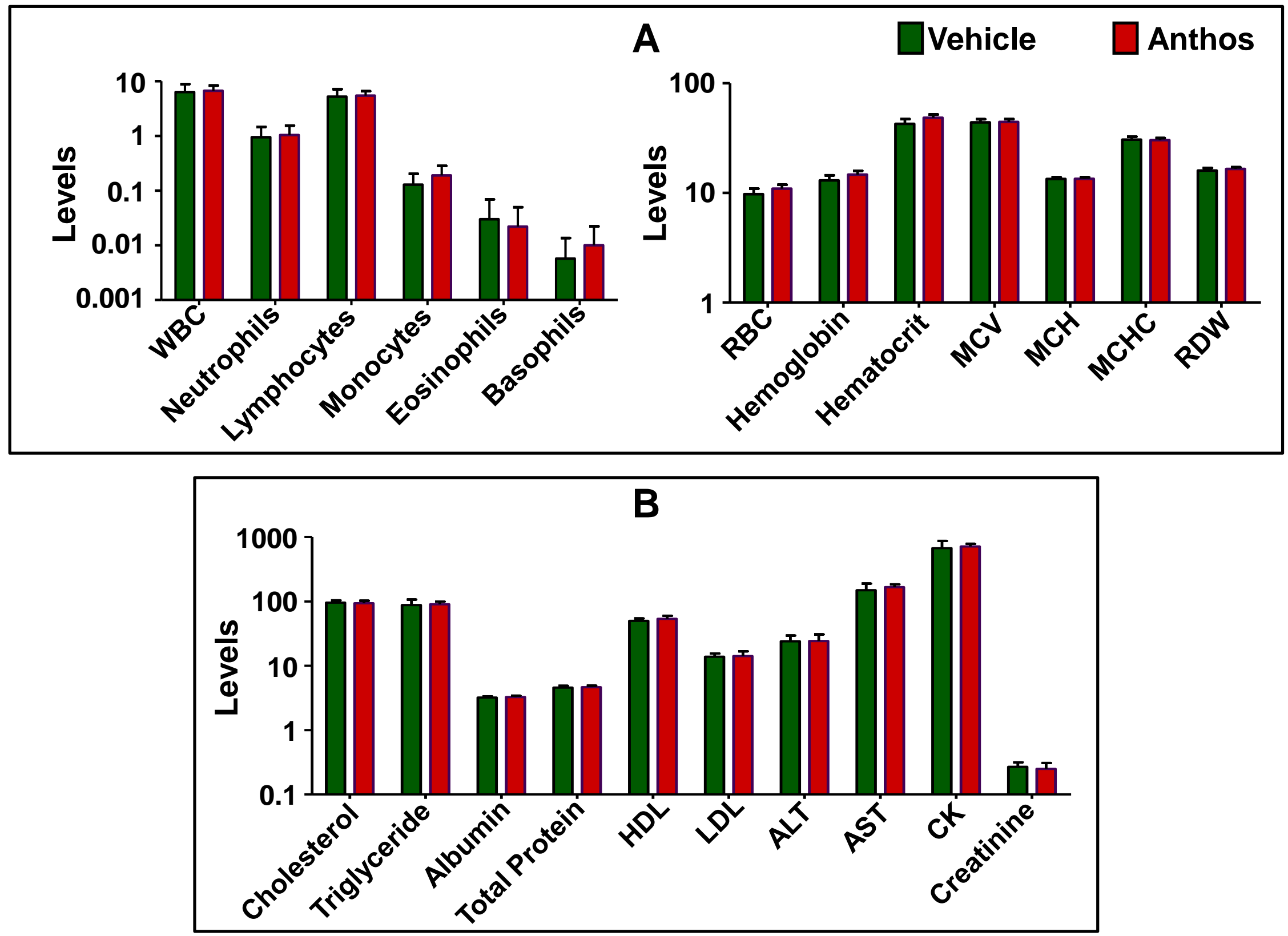
Table I: Antiproliferative activity ( $\mathrm{IC}_{50}$ values) of bilberry-derived Anthos and ExoAnthos against various cancer cell lines.

\begin{tabular}{llccc}
\hline Cancer Type & \multirow{2}{*}{ Cell Line } & \multicolumn{2}{c}{ IC $_{50}(\mu \mathrm{M})$} & \multirow{2}{*}{ Fold Difference } \\
\cline { 3 - 4 } & & Anthos & ExoAnthos & \\
\hline Breast & MCF7 & 2859 & 20 & 143 \\
& MDA-MB-231 & 527 & 49 & 11 \\
Lung & H1299 & 80 & 2 & 40 \\
& A549 & 93 & 9 & 10 \\
Colon & HCT116 & 69 & 18 & 4 \\
Pancreatic & Panc1 & 578 & 65 & 9 \\
& Mia PaCa2 & 960 & 16 & 60 \\
Prostate & DU145 & 221 & 11 & 20 \\
& PC3 & 112 & 9 & 12 \\
Ovarian & Ovca432 & 1281 & 7 & 183 \\
\hline
\end{tabular}

